ARTICLE

DOI: $10.1038 / s 41467-017-00110-9$

\title{
Long-range transport of airborne microbes over the global tropical and subtropical ocean
}

Eva Mayol 1,2, Jesús M. Arrieta (1) 1,3,4, Maria A. Jiménez ${ }^{1,5}$, Adrián Martínez-Asensio 2,5, Neus Garcias-Bonet ${ }^{1,3}$, Jordi Dachs ${ }^{6}$, Belén González-Gaya (10) 6,7, Sarah-J. Royer ${ }^{8,9}$, Verónica M. Benítez-Barrios ${ }^{4,10}$, Eugenio Fraile-Nuez ${ }^{4} \&$ Carlos M. Duarte ${ }^{1,3}$

The atmosphere plays a fundamental role in the transport of microbes across the planet but it is often neglected as a microbial habitat. Although the ocean represents two thirds of the Earth's surface, there is little information on the atmospheric microbial load over the open ocean. Here we provide a global estimate of microbial loads and air-sea exchanges over the tropical and subtropical oceans based on the data collected along the Malaspina 2010 Circumnavigation Expedition. Total loads of airborne prokaryotes and eukaryotes were estimated at $2.2 \times 10^{21}$ and $2.1 \times 10^{21}$ cells, respectively. Overall $33-68 \%$ of these microorganisms could be traced to a marine origin, being transported thousands of kilometres before re-entering the ocean. Moreover, our results show a substantial load of terrestrial microbes transported over the oceans, with abundances declining exponentially with distance from land and indicate that islands may act as stepping stones facilitating the transoceanic transport of terrestrial microbes.

\footnotetext{
${ }^{1}$ Department of Global Change Research, Mediterranean Institute for Advanced Studies (IMEDEA), Spanish Council for Scientific Research - University of the Balearic Islands (CSIC-UIB), Esporles, Mallorca, Spain. ${ }^{2}$ Institute of Littoral, Environment and Societies (LIENSs), National Centre for Scientific Research (CNRS) - University of La Rochelle, La Rochelle, France. ${ }^{3}$ King Abdullah University of Science and Technology, Red Sea Research Center, Thuwal 239556900, Saudi Arabia. ${ }^{4}$ Spanish Institute of Oceanography (IEO), Oceanographic Center of The Canary Islands, Santa Cruz de Tenerife 38180, Spain. ${ }^{5}$ Department of Physics, University of the Balearic Islands (UIB), Palma de Mallorca, Spain. ${ }^{6}$ Department of Environmental Chemistry, Institute of Environmental Assessment and Water Research - Spanish Council for Scientific Research (IDAEA-CSIC), Barcelona, Catalonia, Spain. ${ }^{7}$ Department of Instrumental Analysis and Environmental Chemistry, Institute of Organic Chemistry - Spanish Council for Scientific Research (IQOG-CSIC), Madrid, Spain. ${ }^{8}$ Institute of Marine Sciences - Spanish Council for Scientific Research (ICM-CSIC), Barcelona, Catalonia, Spain. ${ }^{9}$ Daniel K. Inouye Center for Microbial Oceanography, Research and Education, University of Hawaii at Manoa, Honolulu, USA. ${ }^{10}$ OCEOMIC, Marine Bio and Technology S.L., Fuerteventura Technology Park, Puerto del Rosario E35600, Spain. Correspondence and requests for materials should be addressed to E.M. (email: eva.mayol@univ-Ir.fr)
} 
T he atmosphere contains a substantial load of biological particles including bacteria and fungal spores ${ }^{1}$, which may be transported and deposited up to thousands of kilometres away from their source ${ }^{2}$. Average microbial abundances in the atmospheric boundary layer (ABL) around $1.9 \times 10^{4}$ bacteria $\mathrm{m}^{-3}$ and $2.4 \times 10^{4}$ fungal spores $\mathrm{m}^{-3}$ have been reported over land locations ${ }^{3}$. However, there are very few estimates of the abundance of airborne microbes at open oceanic locations ${ }^{1,2}$. As a result of this lack of data, the role of the oceans as a sink and source of airborne microbes to the atmosphere is as yet unresolved $^{4}$. The concentrations of total atmospheric particles and cloud condensation nuclei (CCN) over the ocean are substantially larger (few hundred per $\left.\mathrm{cm}^{3}\right)^{5}$ than those concentrations expected for microorganisms ${ }^{1,2}$. Yet, bacteria and fungal spores may be more important for atmospheric chemistry and physics than what could be expected from their relatively low abundance. It has been hypothesised that the relative small quantity of microorganisms in the atmosphere could be specially important for the formation of ice nuclei (IN) at low latitudes where tropospheric temperatures are relatively high and abiotic particles are not efficient as ice nucleators ${ }^{3}$. In fact, most of the non-biological particles can be active as IN only when temperatures are below $-10^{\circ} \mathrm{C}$ or even in some cases they are active only at temperatures colder than $-20^{\circ} \mathrm{C}^{6}$. Among the biological particles able to contribute to icenucleation are mainly small bacteria and archaea, as well as organic compounds excreted by marine microorganisms, which were described as important IN over remote ocean locations ${ }^{7}$. While biological particles larger than $2 \mu \mathrm{m}$, such as fungal spores, are expected to act as giant CCN generating large drops with fast fall velocity ${ }^{8}$. Estimates of global bacterial emissions to the atmosphere at $40-1800 \mathrm{Gg}$ dry weight $\mathrm{y}^{-1}$ assume a negligible oceanic contribution ${ }^{4}$. Yet, the oceans cover more than $70 \%$ of the Earth's surface and therefore are likely the source and the final destination of a significant fraction of the biological particles suspended in the global atmosphere. In addition, evaluating the role of the oceans as a source and sink of airborne microbes as well as the potential for atmospheric transport of these microbes can provide important insights on the maintenance of microbial diversity 9,10 , connectivity among terrestrial microbial communities and transoceanic spreading of microbes including human ${ }^{11}$ and crop $^{12}$ pathogens.

Here we present a global survey reporting the abundance, fluxes and origin of the airborne microbes hovering over the Atlantic, Indian and Pacific Oceans at low latitudes carried out during the Malaspina 2010 Circumnavigation Expedition. Our data show that the oceans contribute a large fraction of the microbes found in the atmosphere. Moreover, we estimate that airborne microbes travel long distances over the oceans indicating that atmospheric transport of microbes may play a major role in the dispersal of surface marine microbes as well as in the intercontinental transport of their terrestrial counterparts.

\section{Results}

Abundance of airborne microbes over the World's oceans. Abundances of airborne prokaryotes (bacteria and archaea) and unicellular eukaryotes (fungal spores, heterotrophic and autotrophic protists) were measured in 118 air samples collected along the Malaspina 2010 Circumnavigation Expedition that sailed the tropical and subtropical Atlantic, Indian and Pacific Oceans (between $40^{\circ} \mathrm{S}$ and $40^{\circ} \mathrm{N}$, Supplementary Fig. 1).

Microbial abundances in the ABL over the open ocean varied widely among the sampled locations, ranging between $5 \times 10^{2}$ and $8 \times 10^{4}$ cells $\mathrm{m}^{-3}$ of air for prokaryotes (median $6.7 \times 10^{3}$ cells $\mathrm{m}^{-3}$, Fig. 1a), and from $1 \times 10^{2}$ to $1.8 \times 10^{5}$ cells $\mathrm{m}^{-3}$ for unicellular eukaryotes (median $3.2 \times 10^{3}$ cells $\mathrm{m}^{-3}$, Fig. 1b). Median values were consistent with estimated microbial abundances over the ocean from global models ${ }^{3,4}$, while direct microbial counts from previous studies over marine coastal locations were usually closer to the highest prokaryotic abundances ${ }^{13,14}$ and to the median values of eukaryotes ${ }^{15}$ reported in this work. The number of airborne microorganisms is small $(<0.1 \%)$ if compared with the number of aerosols in the oceanic atmosphere, which is dominated by submicron size aerosols ${ }^{5}$. However, the size-dependent distribution of surface and mass (volume) of the aerosol pool do not generally

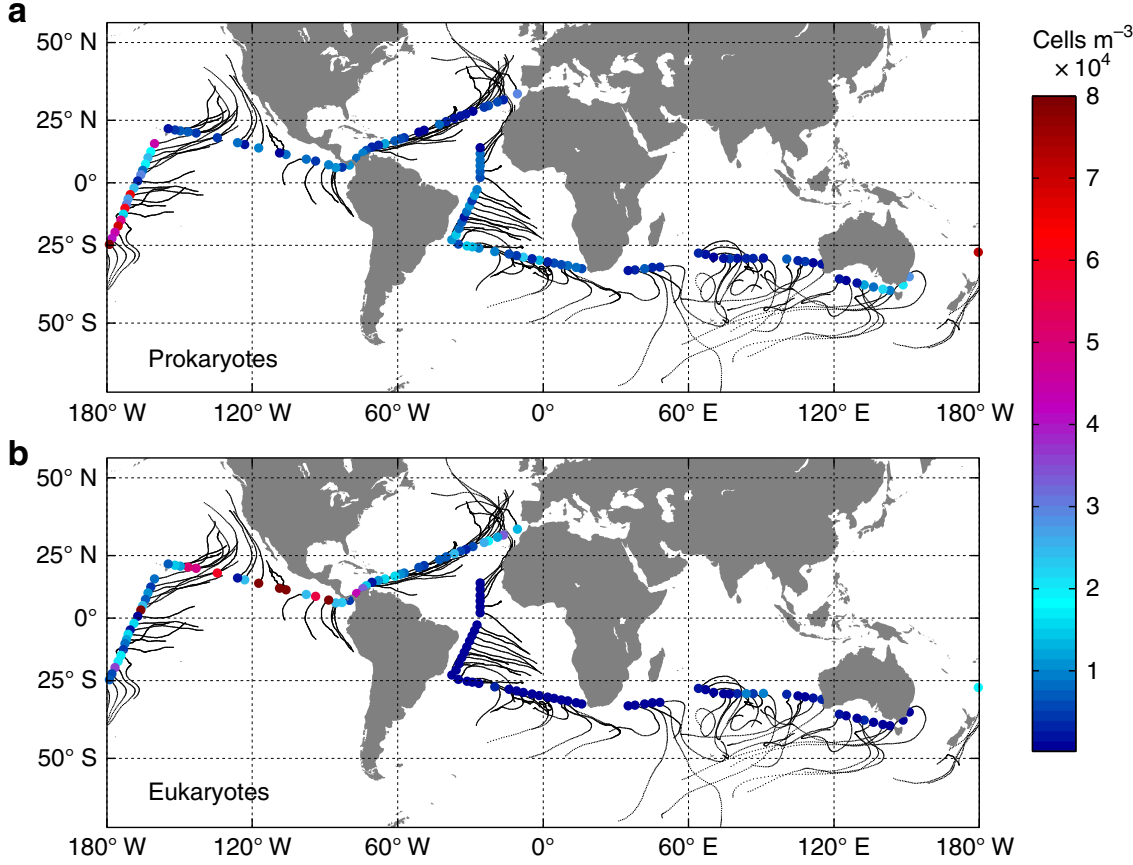

Figure 1 Abundances of airborne microbes over the ocean. Airborne prokaryotic a and eukaryotic abundances b over the Malaspina 2010 Circumnavigation Expedition. Dots correspond to sampled locations and black lines correspond to backward trajectories of air masses modelled for 5 days previous to the air sampling starting at $10 \mathrm{~m}$ above sea level 
a

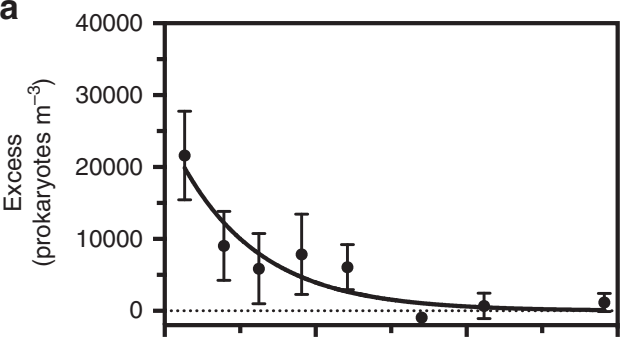

C

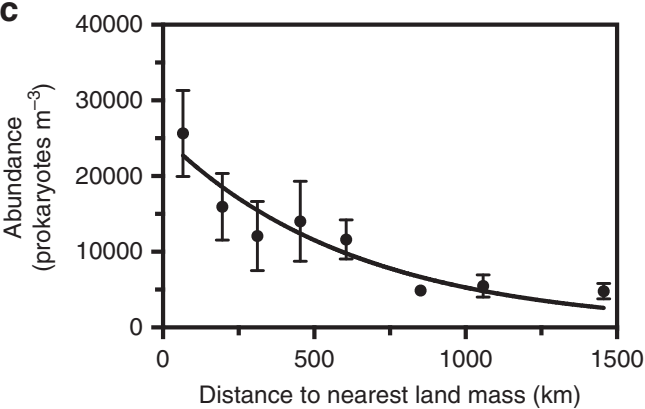

b

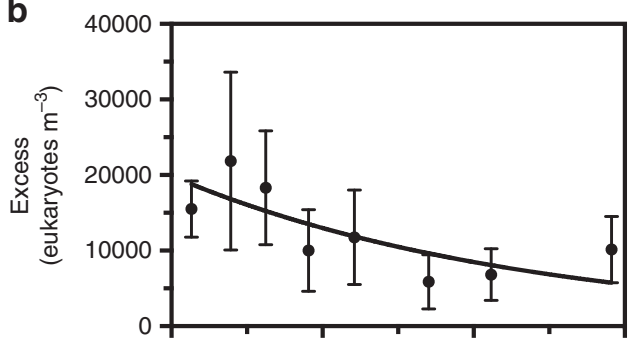

d

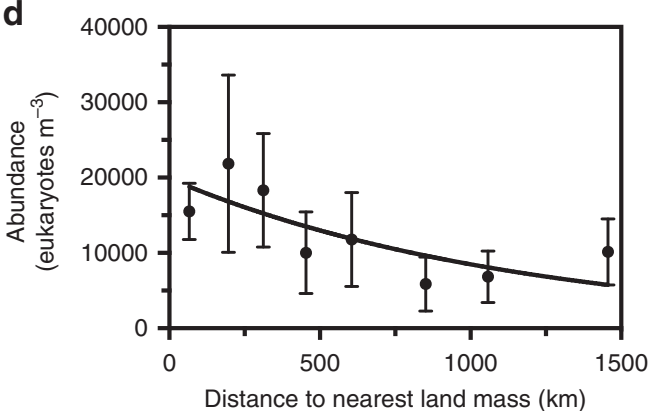

Figure 2 Relationship between the excess and the abundance of microbes with distance to land. The excess of a prokaryotes and $\mathbf{b}$ eukaryotes, and the airborne abundances of $\mathbf{c}$ prokaryotes and $\mathbf{d}$ eukaryotes versus the distance $(D, \mathrm{~km})$ to the nearest land mass. The distance is grouped into 8 bins. Black dots represent the mean values and error bars represent the standard error of the mean (SEM). The solid lines show the fitted exponential models suggested by the Akaike information criterion (AIC) and gives for: a prokaryotic excess (cells $\left.\mathrm{m}^{-3}\right)=25454 \mathrm{e}^{(-0.0037 D)} ; R^{2}=0.87 ; \mathbf{b}$ eukaryotic excess (cells $\left.\mathrm{m}^{-3}\right)=19881 \mathrm{e}^{(-0.00085 D)} ; R^{2}=0.58 ; \mathbf{c}$ prokaryotic abundance (cells $\left.\mathrm{m}^{-3}\right)=25217 \mathrm{e}^{(-0.0016 \mathrm{D})} ; R^{2}=0.88 ; \mathbf{d}$ eukaryotic abundance $\left(\right.$ cells $\mathrm{m}^{-3}$ ) $=$ $19883 \mathrm{e}^{(-0.00085 D)} ; R^{2}=0.58$

follow the distribution of number of aerosols, but shows a maximum for micron-sized aerosols ${ }^{16,17}$. In the oceanic atmosphere, biological aerosols (prokaryotes and eukaryotes) may play a disproportionate role in those processes dependent on the surface and mass of the aerosol population, such as the formation of IN, the absorption/reflection of solar radiation, or especially in terms of atmospheric deposition fluxes of organic matter. Indeed, settling velocities for large aerosols (several microns) are known to be larger than those of submicron aerosols ${ }^{18}$, and the overall deposition flux of organic matter is strongly dependent on the fraction of large aerosols.

Microbial contribution of land and oceans to the atmosphere. We constrained the potential role of the surface ocean as a source of atmospheric prokaryotes and unicellular eukaryotes using a simple model considering only spray inputs into the atmosphere and losses by deposition estimated using previously reported parameterisations ${ }^{19,20}$. Thus, obviating advection, the concentration of airborne microbes that can be provided by the surface ocean would be that in the steady state between spray inputs and deposition. This depends mainly on the abundance of microbes in surface water and wind speed, and to a lesser extent on other parameters such as humidity and temperature in the used parameterisations. These estimated ranges are towards the low range of our estimates. In fact, $32 \%$ of the sampled locations greatly exceeded the prokaryotic abundances calculated from purely local oceanic contributions estimated from the in situ environmental conditions and abundances in surface waters, or to put in another way, $32 \%$ of the samples showed a high prokaryotic excess. In contrast, the eukaryotic cells largely exceeded the calculated marine contribution in all of the samples, suggesting that air samples included allochthonous eukaryotes advected from other locations. Many samples presenting prokaryotic abundances higher than the estimated oceanic range were located in the vicinity of the numerous islands found in the West and Central Pacific regions (Fig. 1, regions described in
Supplementary Fig. 1). The abundance of airborne prokaryotes observed close to islands and continents exceeded the predicted oceanic contribution by, on average, $2.5 \times 10^{4}$ cells $\mathrm{m}^{-3}$, well in the range of the average abundance of $2 \times 10^{4}$ cells $\mathrm{m}^{-3}$ reported over land locations ${ }^{3}$. This prokaryotic excess was higher near the coast and decreased exponentially with distance away from the nearest land mass (Fig. 2), suggesting that the higher prokaryotic abundances as compared to those expected from a local marine contribution were mainly of terrestrial origin. Indeed, the absence of correlation between airborne microbial abundances and other atmospheric and oceanographic parameters, such as wind speed, waves and chlorophyll- $a$ data, suggests that those factors play a minor role as compared to terrestrial inputs in controlling the variability observed in airborne microbial abundances among locations (Supplementary Table 1 and Supplementary Fig. 2).

Atmospheric transport of microbes. Unicellular eukaryotic abundances also showed a decreasing trend when moving away from land (Fig. 2). The maximum eukaryotic values were found in the North Atlantic and East Pacific, where most of the prokaryotic abundances were substantially lower than those of eukaryotes even at locations far from the coast (Supplementary Fig. 3a). These results can be explained because the North Atlantic and East Pacific regions, sampled during summer and spring, respectively, were probably affected by the typical events of African dust exports to the Atlantic Ocean during summer and Asian dust exports into the Pacific during spring ${ }^{21}$. In fact, Moderate-Resolution Imaging Spectroradiometer (MODIS) reported high values of aerosol optical depth (AOD) over the East Pacific and Atlantic during May and especially highest over the Atlantic during June $2011^{22}$. Moreover, the expected terrestrial origin of eukaryotes is consistent with the lack of phytoplanktonic microorganisms observed under the microscope in the analysed air samples, with the high fungal spore abundances previously found in coastal areas collected during dust storms ${ }^{23}$, and with the fact that fungal spores made the bulk of the eukaryotic counts. 

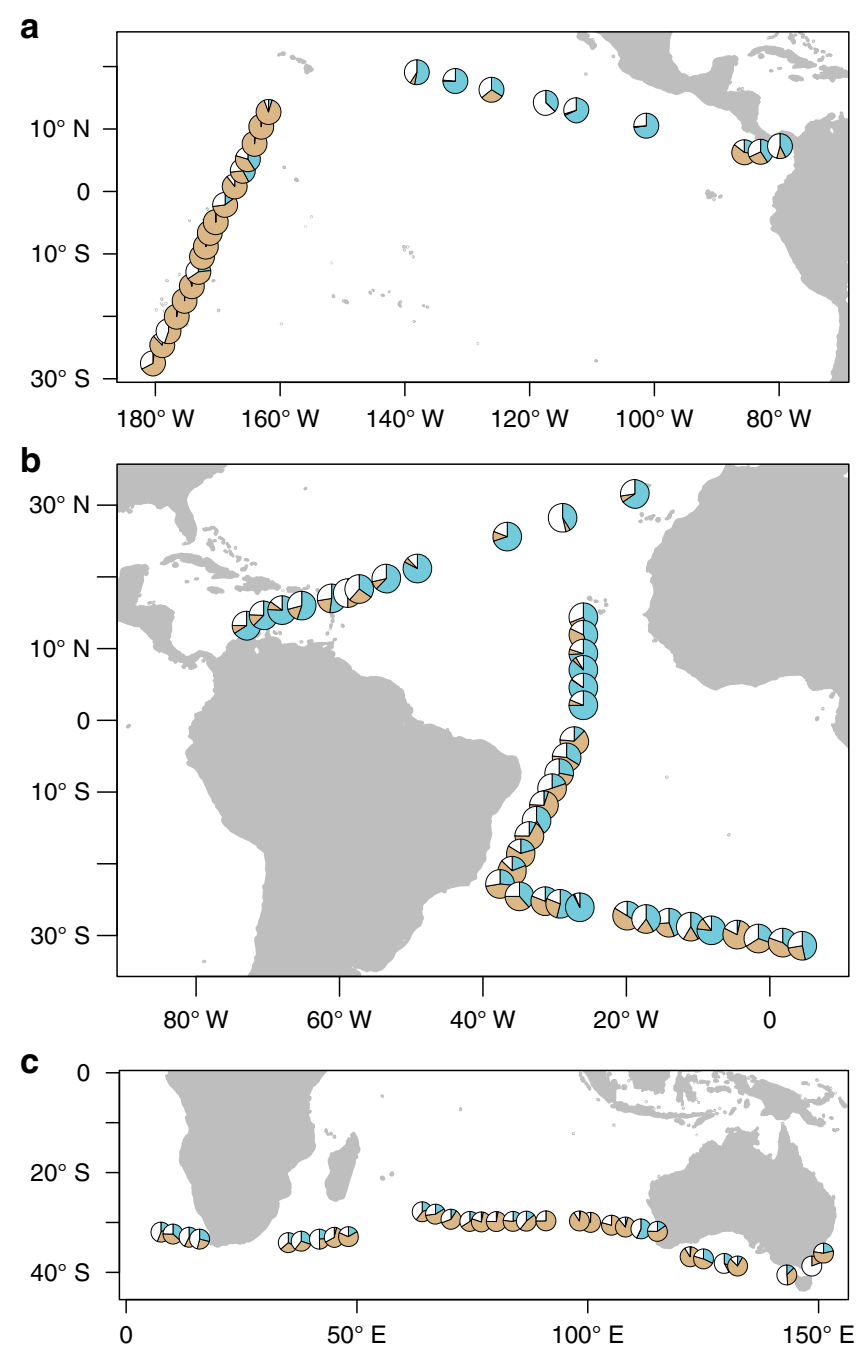

Figure 3 Origin of the prokaryotic sequences. The pie charts represent the estimated proportion contributed by marine (blue), terrestrial (brown) and unknown (white) sources for the 99 sampled locations over the Pacific a, Atlantic $\mathbf{b}$ and Indian $\mathbf{c}$ oceans where we could get sequence information. Please note that the different panels have different scales. Data available in Supplementary Table 2

In addition, the observed increment in the ratio between eukaryotes and prokaryotes with distance to land (Supplementary Fig. $3 b, c)$ is in agreement with the observed ability of some spores to remain suspended in the air for extended periods of time $^{24}$.

Despite the strong loss of atmospheric microbes with the distance to the coast, the abundance of prokaryotes at locations $1000 \mathrm{~km}$ away from land was about $20 \%$ of that found at locations close to the coast (Fig. 2). This value is somewhat smaller than the estimated $30-50 \%$ of total aerosols able to exceed distances of $1000 \mathrm{~km}$ from tropical and temperate sources ${ }^{25}$. Moreover, at these locations the relationship between prokaryotic excess and distance to the nearest land mass predicted that $2.5 \%$ of prokaryotic excess remain suspended in the atmosphere, which means that a fraction of the allochthonous input of microbes has the potential for long-range or even transoceanic transport.

Sources of airborne microbes. Independent confirmation on the origin of airborne microbes (Fig. 3) was obtained by comparing the phylogenetic affiliations of airborne prokaryotes with those found in surface seawater samples collected in the Malaspina
Expedition (Supplementary Fig. 1), and in different datasets from marine and terrestrial ecosystems (see Methods). Overall, airborne microbial assemblages could be explained by a mixture of about $25 \%$ of microbes from marine origin with about $42 \%$ of terrestrial microorganisms (median values). A relatively large fraction (median 24\%) could not be explained by our reference data set suggesting either terrestrial sources or marine contributions from remote areas not represented in our reference data set. This indicates that long-range dispersal of airborne prokaryotes and substantial inputs from non-marine sources shape the composition of airborne microbial assemblages. The regions where the largest excess of prokaryotes relative to the potential marine contribution were estimated (West and Central Pacific, Supplementary Fig. 4a) showed the lowest percentage of marine sequences $(1 \%$ and $2 \%$ respectively, Fig. $3 \mathrm{~b}$, Supplementary Fig. 4b), a clear dominance of terrestrial sequences (around 90\%, Fig. 3b, Supplementary Fig. 4c), and a small percentage of sequences not found in our marine reference data set $(5 \%$ and $8 \%$, respectively, Fig. 3b, Supplementary Fig. 4d). This is consistent with a high excess of prokaryotes predicted over these regions, where most of the air samples were located relatively close to land resulting in the dominance of advective flows (Supplementary Fig. 4e). Unexpectedly, terrestrial prokaryotic sequences and those not present in the databases comprised more than half of the sequences detectable in the South Atlantic and Indian Oceans, two regions located far from land and apparently influenced by air masses of marine origin (Supplementary Fig. 1). In fact, marine sequences only represented $35 \%$ and $15 \%$ of the total of those detected over the South Atlantic region and the Indian Ocean, respectively (Fig. 3a, c, Supplementary Fig. 4b). The high contribution of terrestrial sequences relative to those of marine origin is consistent with the high concentrations of urban aerosols found over these regions during the Malaspina 2010 Circumnavigation Expedition ${ }^{26}$. This was probably due to plumes of particles released from land and vertically mixed at altitudes above the boundary layer, which have been described as a frequent phenomenon over the tropical Indian Ocean ${ }^{27}$. Indeed, most of the air trajectories in the Indian Ocean and some of those in the South Atlantic reached altitudes higher than $1000 \mathrm{~m}$ that typically exceed the altitude of the ABL (Supplementary Figs. 5 and 6). At these altitudes airborne particles can be advected from land to the ocean where they can easily mix down to lower altitudes because the thermal inversion at the top of the boundary layer is weaker in the Indian Ocean than in other locations ${ }^{27}$, enhancing the bacterial exchange at the top of the boundary layer. However, around $30 \%$ of the community composition found over the Indian Ocean could not be attributed to either terrestrial or marine sources, suggesting a significant contribution of remote sources not included in our reference dataset. The Central Atlantic was characterised by low prokaryotic abundances consistent with those expected from a marine origin and represented the highest percentages of marine sequences (Fig. 3a, Supplementary Fig. 4b). Back trajectory analysis showed that the air masses sampled in the Central Atlantic were originated from land locations. However, these stations were among those situated farthest away from the closest land point, which could explain the dominance of marine phylotypes in these samples. The North Atlantic region showed a prevalence of marine sequences (median slightly over $60 \%$ ), in agreement with the observed abundances of airborne prokaryotes that were close to those expected under equilibrium with the surface ocean (on average $-1160 \pm 1760$ prokaryotic cells below or above equilibrium) in $77 \%$ of the North Atlantic locations, while the East Pacific region showed a prevalence of marine and undetermined contributions (medians slightly over 35\%, Fig. 3, Supplementary Fig. 4). This high percentage of undefined sequences could be associated with the high 
numbers of observed eukaryotes, probably coming from land, over this region, suggesting that at least a portion of these undefined sequences can correspond to prokaryotes derived from long-range transport from land locations. Moreover, a large percentage of fungal mitochondrial sequences was detected in many samples while plastids and other marine eukaryotic sequences that frequently appear in $16 \mathrm{~S}$ rDNA surveys made a very low contribution to almost all of the samples (Supplementary Table 2). This is in agreement with the microscopic observations where we found abundant fungal spores but very few cells of phytoplankton or other marine eukaryotes.

The whole-community approach used to estimate the relative contribution of marine versus terrestrial OTUs did not use the phylogenetic assignment of each sequence, and therefore is free of dubious assumptions as to the attribution of a terrestrial or marine origin to each individual sequence. However, the comparison among airborne and ocean surface communities yields strong indications as to the terrestrial origin of a large fraction of the airborne sequences. This includes the prevalence of Betaproteobacteria, Actinobacteria and Bacilli found in airborne samples (Supplementary Fig. 7). These groups are practically absent in the reference surface seawater samples collected during the Malaspina Expedition (Supplementary Fig. 7) and are generally rare in marine environments elsewhere, but abundant in freshwater and terrestrial environments ${ }^{28}$.

Exchange of microbes between the ocean and the atmosphere. The role of the oceans as a sink and source of airborne microbes to the atmosphere was evaluated by estimating deposition and emission fluxes in the sampled locations. Dry deposition fluxes ranged between $1 \times 10^{4}$ and $6 \times 10^{6}$ prokaryotic cells $\mathrm{m}^{-2}$ day $^{-1}$ and between $1 \times 10^{4}$ and $2 \times 10^{7}$ eukaryotes $\mathrm{m}^{-2}$ day $^{-1}$ (Supplementary Table 3 ), and were generally higher (Wilcoxon matched-pairs signed rank test, $P_{\text {prokaryotes }}=0.052, P_{\text {eukaryotes }}<$ 0.0001 ) than the corresponding emission fluxes, which ranged between $1 \times 10^{3}$ and $2 \times 10^{6}$ prokaryotic cells $\mathrm{m}^{-2}$ day $^{-1}$ and between 1 and 2000 eukaryotes $\mathrm{m}^{-2}$ day $^{-1}$ (Supplementary Table 3). The prevalence of net depositional microbial fluxes indicates that the ocean mainly acts as a sink for airborne microbes, largely originating from terrestrial sources. There were 12 rain precipitation events recorded during the track of the Malaspina Expedition, but only 8 of these events were relatively close in time to 10 of the air sampled locations (Supplementary Table 1) although rain events never coincided with sampling operations. We estimated wet deposition of prokaryotes and eukaryotes for the sampling sites closest to the rainfall events (see Supplementary Methods). Although these estimates were substantially higher than dry deposition fluxes, consistent with the high efficiency of rain to scavenge aerosols ${ }^{29}$, only one location associated to a rain event showed a large decrease in both airborne prokaryotic and eukaryotic abundances as compared to the previous sample, while the remaining nine locations close to rain events showed minor decreases or even increasing abundances for both prokaryotes and eukaryotes as compared to the values observed in the previous sample (Supplementary Fig. 8). Episodic events of wet deposition may have a large impact on the local abundance of airborne microbes over short periods of time in the range of hours. However, rain events were rare during the Malaspina Expedition and therefore wet deposition is unlikely to have a measurable effect in our measurements.

Dry deposition fluxes indicate that $50 \%$ of prokaryotic and eukaryotic cells settled after a median of 17 and 3.5 days, respectively. Using a dispersion model ${ }^{30}$, we estimated that $50 \%$ of the airborne prokaryotes and eukaryotes remain suspended after being transported over 22000 and $6000 \mathrm{~km}$ into the ABL, respectively (Supplementary Table 3). This is sufficient to allow intercontinental transport depending on wind direction. It must be noted that over some regions of the ocean where rain events are more frequent the residence times are expected to be shorter than those reported in this study ${ }^{31}$ due to the enhanced removal by wet deposition resulting in reduced residence times and potential transport distances.

Global marine contribution of microbes to the atmosphere. Our results indicate that the atmosphere over the open ocean harbours abundances of airborne prokaryotes between $5 \times 10^{2}$ and $8 \times 10^{4}$ cells $\mathrm{m}^{-3}$. By constraining prokaryotic abundances in the surface ocean to a typical range from $0.5 \times 10^{6}$ to $1.5 \times 10^{6}$ cells $\mathrm{ml}^{-1}$ and using wind speeds larger than $6 \mathrm{~m} \mathrm{~s}^{-1}$, representative of open-ocean conditions ${ }^{32}$, we can attempt to estimate the magnitude of oceanic contributions to global airborne microbial abundance. Using these constrains and the same steady-state model used to calculate the oceanic contribution to microbial abundance in our samples, we estimate that prokaryotic emissions from the ocean support abundances of about $3 \times 10^{3}$ to $1.3 \times 10^{4}$ cells $\mathrm{m}^{-3}$ (Supplementary Fig. 9) while higher abundances are typically found close to islands and land masses showing substantial inputs of terrestrial microbes. However, the ocean covers more than $70 \%$ of the Earth's surface and the calculated atmospheric boundary layer over the oceans is on average thicker than over land ${ }^{33}$, which results in oceanic prokaryotes contributing roughly between 33 and $68 \%$ of the prokaryotes present in the global atmosphere. Our data also show that terrestrial microbes reach far out into the ocean and can represent a large fraction of the microbes found over oceanic locations at least at the low to mid-latitudes surveyed here.

Upscaling over the ocean the load of airborne microbes across a grid of $1^{\circ} \times 1^{\circ}$ between $40^{\circ} \mathrm{S}$ and $40^{\circ} \mathrm{N}$ using the exponential model fit with distance from the nearest land mass (Supplementary Fig. 10) we estimated a total load of $2.2 \times 10^{21}$ prokaryotes and $2.1 \times 10^{21}$ eukaryotes over the global ocean (Fig. 4). Yet, these stocks are the result of a constant exchange involving a much larger number of microbes. We estimated that gross emission fluxes of airborne microbes over the ocean between $40^{\circ} \mathrm{S}$ and $40^{\circ}$ $\mathrm{N}$ ranged from $7.5 \times 10^{21}$ to $2.3 \times 10^{22}$ prokaryotes $\mathrm{y}^{-1}$ and from $7.5 \times 10^{18}$ to $2.3 \times 10^{19}$ eukaryotes $\mathrm{y}^{-1}$, while gross estimated deposition fluxes reached $2.3 \times 10^{22}$ prokaryotes and $1.6 \times 10^{23}$ eukaryotes $\mathrm{y}^{-1}$, resulting in a net depositional fluxes of up to $1.5 \times 10^{22}$ prokaryotes and about $1.6 \times 10^{23}$ eukaryotes $\mathrm{y}^{-1}$ (Fig. 4). The net deposition fluxes into the ocean were equivalent to a carbon mass of up to $2.0 \times 10^{-4} \mathrm{Tg} \mathrm{C} \mathrm{y}^{-1}$ for prokaryotes and about $2.1 \mathrm{Tg} \mathrm{C} \mathrm{y}^{-1}$ for eukaryotes, comparable to the emissions calculated from land sources ${ }^{4}$.

In summary, the results presented improve on prior attempts at producing global budgets of microbial abundance in the atmosphere by providing reliable measurements of airborne microbial abundance at offshore locations, constraining the marine versus terrestrial origin of airborne microbes over the ocean, and demonstrating the role of islands in maintaining elevated levels of airborne organisms over the ocean accounting for the high concentrations observed in the subtropical Pacific (Fig. 1). Moreover, our calculations show that the residence times of 17 and 3.5 days may suffice to transport airborne prokaryotes and eukaryotes over thousands of kilometres. Hence, the global atmosphere plays an important role both in the intercontinental transport of terrestrial microorganisms and in the dispersal of oceanic microbes across distant oceanic regions, with islands acting as stepping-stones for cross-oceanic transport of terrestrial microbes. 


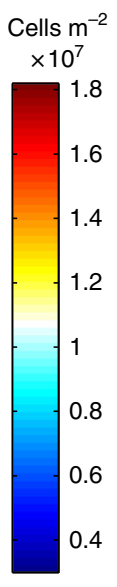

C

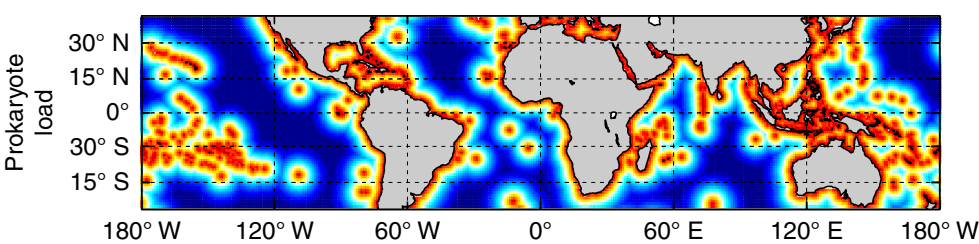

b
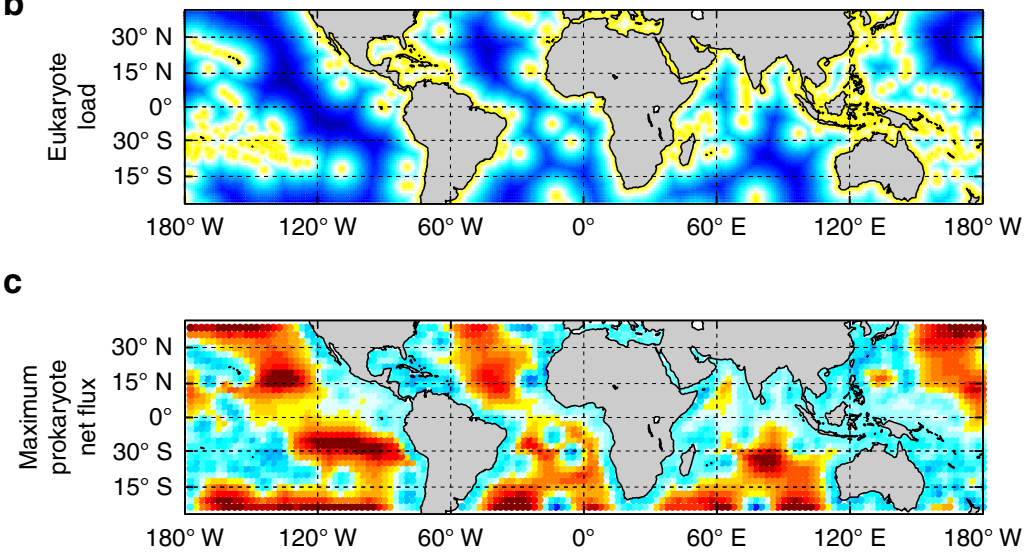

d
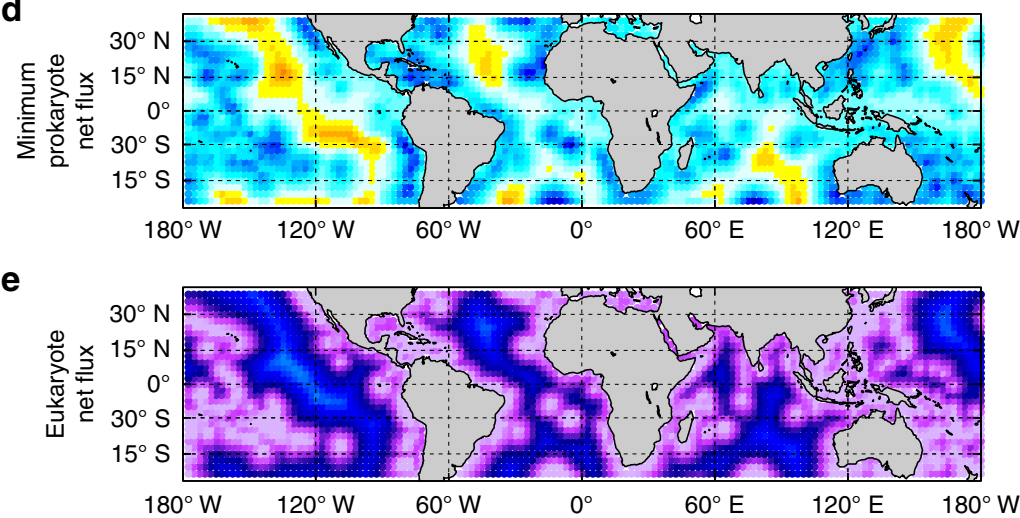

Cells $\mathrm{m}^{-2} \mathrm{~s}^{-1}$

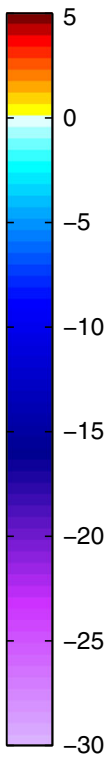

Figure 4 Microbial loads and air-sea exchange fluxes over the global tropical and subtropical ocean. Prokaryotic load $\mathbf{a}$ and eukaryotic load $\mathbf{b}$ over the ocean extension compressed between $40^{\circ} \mathrm{S}$ and $40^{\circ} \mathrm{N}$ with resolution of $1^{\circ} \times 1^{\circ}$; maximum net fluxes of prokaryotes considering high spray fluxes $\mathbf{c}$ and low spray fluxes $\mathbf{d}$; and net fluxes of eukaryotes e considering high spray fluxes (the differences between net fluxes of eukaryotes using high or low spray fluxes were negligible) with resolution of $2.5^{\circ} \times 2.5^{\circ}$. Negative values indicate net deposition fluxes

\section{Methods}

Study area. Samples of airborne microbes were collected along the Malaspina 2010 Circumnavigation Expedition ${ }^{34}$ on board the R/V Hespérides from December 2010 to July 2011 collecting samples over 118 locations across the Atlantic, Pacific and Indian Oceans (Supplementary Fig. 1). According to the atmospheric circulation of the study area, characterised using atmospheric monthly field data obtained from the NCEP/NCAR atmospheric reanalysis ${ }^{35}$, most samples were taken near the Inter Tropical Convergence Zone (ITCZ) where the winds are relatively weak and typically prevailing from the east. The trade winds converging along the ITCZ come from NE in the Northern Hemisphere and from SE in the Southern Hemisphere. The position of the ITCZ (around the equator) migrates from the Southern to the Northern Hemisphere between January and July over the Indian and Pacific Oceans but it does not significantly change in the Atlantic Ocean during the same period of time. The North Atlantic region is characterised by the presence of strong northeasterly winds, enhancing the transport of biological particles across the Atlantic from Europe. When the South Atlantic region was sampled (February 2011) the wind direction was mainly from SE, and from NE close to Equator, indicating that the ITCZ was crossed during sampling. The West Pacific Region was characterised by weak winds from the South, while in the Central Pacific Region stronger winds were from the East. In summer, the East Pacific Region was characterised by moderate winds from NE and by weak southerly winds close to Central America. However, during winter season the winds were slightly stronger and were coming from NE. The Indian Region was influenced by the trade winds at the North and by the strong westerly winds at the South.
Collection of airborne microbes. Air sampling was carried out using a commercially available cyclonic collector (Coriolis- $\Delta$, Bertin Technologies ${ }^{36}$ ) placed at bow-side at $\sim 10 \mathrm{~m}$ height over sea level at the top deck of the R/V Hespérides. The collector was operated using the procedures described earlier ${ }^{2}$. Briefly, air was drawn into the sampler at $3001 \mathrm{~min}^{-1}$ for $6 \mathrm{~h}$ (equivalent to $108 \mathrm{~m}^{3}$ ), and the collection liquid was refilled continuously by the system at a rate sufficient to match the loss of liquid by evaporation and re-aerosolisation measured during a previous 10 min run. Daily, a field blank was collected by sampling air for 2 min (equivalent to $0.6 \mathrm{~m}^{3}$ ). Samples were processed immediately after collection and the volume was adjusted to $15 \mathrm{ml}$ with additional collection liquid if necessary.

Microbial abundance and biomass. Prokaryotes and unicellular eukaryotes were counted in $5 \mathrm{ml}$ aliquots of the air samples by epifluorescence microscopy (Leika DM 1000) following the procedures outlined in Mayol et al. ${ }^{2}$. The fraction of protists from total eukaryotic counts was determined using the blue excitation light at $480 \mathrm{~nm}$, which allows the detection of chlorophyll pigments as a red-colour particle in autotrophic protists. Heterotrophic protists were expected to be in similar quantities than those of autotrophic protists, assuming that they are in a similar proportion in seawater. Thus, fungal spores were expected to be the remaining fraction. A minimum of 150 prokaryotes and unicellular eukaryotes were counted per sample in at least 12 different fields, or a minimum of 150 fields were counted for samples with lower abundances. Microbial losses by re-aerosolisation were corrected as described earlier ${ }^{2}$. 
Additionally, we determined bacterial abundance in surface seawater by flow cytometry of SYBRGreen I stained samples ${ }^{37}$ to be used in the calculation of spray fluxes. The seawater was collected from the first metres $(<5 \mathrm{~m}$ depth) of the mixed layer with Niskin bottles mounted on a rosette sampling system.

Microbial abundances were converted into $\mathrm{C}$ biomass using standard conversion factors of $12.4 \mathrm{fg} \mathrm{C}$ cell $^{-1}$ for prokaryotes ${ }^{38}$ and $13 \mathrm{pg} \mathrm{C}^{-1 l^{-1}}$ for fungal spores $^{39}$.

Microbial load. The microbial load in the boundary layer was estimated as the product between the measured microbial abundances in the air and the height of the $\mathrm{ABL}$ obtained from the Analysis of the European Center for Medium-range Weather Forecasts (ERA-Interim ${ }^{40},{ }^{41}$ ) assuming that well-mixed conditions prevail $^{42}$.

Microbial identification by sequencing. The remaining $10 \mathrm{ml}$ of the air samples were filtered through a $0.22 \mu \mathrm{m}$ pore-size polycarbonate filter and stored at $-80^{\circ} \mathrm{C}$. DNA was extracted from filters using a commercial kit (UltraClean ${ }^{\circledR}$ Soil DNA Isolation Kit, Mobio). In order to optimise the DNA yield, the filters were previously homogenised in a bead homogenizer (Precellys, Bertin Technologies) using autoclaved glass beads $(0.5 \mathrm{~mm})$ for $30 \mathrm{~s}$ at 2500 r.p.m. Nucleic acid extracts were stored at $-20^{\circ} \mathrm{C}$ until amplification. The V4 region of the $16 \mathrm{~S}$ rDNA gene was amplified by PCR using primers $515 \mathrm{~F}\left(5^{\prime}\right.$-GTGCCAGCMGCCGCGG TAA-3') and 806 R (5'-GGACTACHVGGGTWTCTAAT-3') suitable for amplification of most bacteria and archaea ${ }^{43}, 44$, generating $~ 250$ bp amplicons suitable for community analysis ${ }^{45}$. The forward primer $(515 \mathrm{~F})$ contained a $454-\mathrm{B}$ pyrosequencing adapter with a GA linker while the reverse primer (806 R) was linked by a AC linker to a unique $12 \mathrm{bp}$ barcode sequence identifying each sample followed by a AG linker and a Roche 454-A sequencing adapter. Each $20 \mu \mathrm{l} \mathrm{PCR}$ reaction contained $5 \mu \mathrm{l}$ of template DNA plus (final concentrations), $10 \mathrm{mM}$ of dNTPs mixture, $5 \mu \mathrm{M}$ of each primer and 0.01 units of Taq Polymerase (Takara) suspended in the buffer provided by the manufacturer. Additional negative control reactions (without DNA) were run with each batch of PCR reactions to check for possible contamination. The PCR consisted of an initial denaturing step at $94{ }^{\circ} \mathrm{C}$ for $3 \mathrm{~min}, 30$ cycles of standard amplification $\left(94^{\circ} \mathrm{C}\right.$ for $45 \mathrm{~s}, 50^{\circ} \mathrm{C}$ for $60 \mathrm{~s}$ and $72^{\circ}$ C for $90 \mathrm{~s}$ ) with a final elongation step of $72^{\circ} \mathrm{C}$ for $10 \mathrm{~min}$. The PCR products were checked by electrophoresis on $2 \%$ agarose gels. For each sample, we performed at least two independent PCR reactions and the products were pooled. The amplification products were cleaned and purified from dNTPs, primers and PCR reaction mix components using Ampure magnetic beads (Agencourt ${ }^{\circledR}$ AMPure ${ }^{\circledR}$ XP, Beckman Coulter). Purification and primer removal were checked by agarose electrophoresis. After purification and prior to sequencing, the DNA content of all purified PCR amplification products were quantified by using Quant-iT dsDNA Assay Kit (Invitrogen). The sequences generated were processed using the QIIME 1.8.0 software pipeline ${ }^{46}$ for quality control, demultiplexing according to the unique $12 \mathrm{bp}$ barcodes, denoising, screening for chimeras and binning of phylotypes at a $97 \%$ similarity threshold. Only samples resulting in $>800$ quality controlled reads $>200$ bp were considered for the analysis. OTUs were assigned a phylogenetic affiliation by comparison with the SILVA database release $111^{47}$. We did not use the phylogenetic affiliation as an indication of terrestrial or marine origin because of the limited resolution afforded by short sequences for most OTUs was unlikely to provide unequivocal evidence of their origin for many of the OTUs. Instead, we used a more robust community-wide approach by comparing the whole airborne communities to a set of reference end-member communities from different sources. A reference database was constructed to represent a range of terrestrial and marine environments using surface seawater samples ( $<5 \mathrm{~m}$ depth) collected at 36 locations along the track of the Malaspina 2010 Circumnavigation Expedition plus additional 83 data sets using the same primer (Supplementary Table 4 ) from the SRA. This reference data set comprising a total of 119 samples was divided into two categories (terrestrial and marine) and used for attributing the relative contribution of marine and terrestrial sources to each of the airborne microbial assemblages using a community-wide approach by means of the software package 'Source Tracker" ${ }^{48}$

Atmospheric parameters. Wind speed, air temperature, atmospheric pressure and humidity were measured in situ along the Malaspina 2010 Circumnavigation Expedition. These atmospheric parameters were extracted as 2 -min average values from the continuous recording of the meteorological station installed on board the $\mathrm{R} / \mathrm{V}$ Hespérides. In addition, volumetric measurements of precipitation were made from the rain collected in recipients placed on the top deck of the ship.

Deposition flux. The dry (not associated to snow or rain conditions) deposition flux of airborne microorganisms ( $\mathrm{Fd}$, cells $\mathrm{m}^{-2} \mathrm{~s}^{-1}$ ) estimated for each sampled location was computed following Jurado et al. ${ }^{17}$ based on the formulation of Williams ${ }^{49}$ according to the equation

$$
\mathrm{Fd}=v_{\mathrm{d}} \times C_{\text {air }}
$$

where $v_{\mathrm{d}}$ is the deposition velocity (in $\mathrm{m} \mathrm{s}^{-1}$ ) and $C_{\text {air }}$ is the concentration of airborne microorganisms $\left(\right.$ cells $\mathrm{m}^{-3}$ ). The meteorological parameters needed to compute $v_{\mathrm{d}}$ (wind speed, temperature, humidity and pressure) were taken from the underway observations performed in the R/V Hespérides and averaged over the $6 \mathrm{~h}$ of sampling. The small sigma values of these averages (not shown) indicate that nearly steady-state conditions were present during sampling period at almost all the locations sampled. We assumed a density of $1.1 \mathrm{~g} \mathrm{~cm}^{-3}$ for biological particles $^{50}$ and a mean diameter of 0.5 and $5 \mu \mathrm{m}$ for prokaryotes and fungal spores respectively, as determined by epifluorescence microscopy.

Spray flux. The sea-spray flux (Fs, cells $\mathrm{m}^{-2} \mathrm{~s}^{-1}$ ) estimated for all samples was computed using the microbial abundances measured in seawater as

$$
F \mathrm{~s}=\dot{V}_{\mathrm{T}} \times C_{\text {water }}
$$

where $\dot{V}_{\mathrm{T}}$ is the spray velocity estimated as the total volume flux of seawater spray into the atmosphere $\left(\mathrm{m}^{3} \mathrm{~m}^{-2} \mathrm{~s}^{-1}\right)$ and $C_{\text {water }}$ is the microbial abundance in sea surface water samples $\left(\right.$ cells $\mathrm{m}^{-3}$ ). As discussed in an earlier publication ${ }^{2}, \dot{V}_{\mathrm{T}}$ is computed using the formulations of $\mathrm{Gong}^{51}$ and considering a range of radii from 0.2 to $10 \mu \mathrm{m}$. Averaged values of the meteorological conditions (wind speed, temperature and humidity) registered by on board system of the R/V Hespérides during the $6 \mathrm{~h}$ of sampling were used in this calculation.

Oceanic contribution to the pool of airborne microbes. In the absence of allochthonous inputs from land, the microbial abundance over oceanic location can be estimated as the result of the opposed fluxes of aerosolisation by spray formation and deposition. Thus, using the parameterisations of spray and deposition flux described above, the concentration of airborne microbes expected from local oceanic contributions can be estimated for the steady state where the deposition flux equals spray flux for the ambient conditions measured in situ. Following this methodology, the value of expected $C_{\text {air }}$ was computed for each sample with the values measured of $C_{\text {water }}$ and the averaged values of the meteorological magnitudes. The mixing processes related to the turbulence operate at time-scales shorter than our $6 \mathrm{~h}$ sampling period ${ }^{52}$. Therefore, well-mixed conditions are present and the dilution by turbulent motion is included in this balance. The departure between the observed and estimated $C_{\text {air }}$ indicates the contribution of advective processes.

In a similar manner, we could constrain the range of global oceanic contributions because prokaryotic abundance at most locations in the surface ocean falls within a relatively narrow range from $5 \times 10^{5}$ to $1.5 \times 10^{6}$ prokaryotes $\mathrm{ml}^{-1}$ and the equilibrium depends mainly on the microbial abundances in surface waters and wind speed and to a lesser extent on the other meteorological variables used to calculate fluxes. Therefore, we estimated global oceanic contributions using standard conditions $\left(T=25^{\circ} \mathrm{C}, \mathrm{RH}=80 \%, P=1025 \mathrm{hPa}\right)$ and a range of wind speeds and prokaryotic abundances encompassing the range commonly found in the ocean ${ }^{53}$ (Supplementary Fig. 9). This calculations assume non-preferential aerosolisation of microbes in the surface ocean, even if there is evidence indicating that microbes may be concentrated by bubbles and then aerosolisation rates may be higher than those expected from a homogeneous distribution microbes in the water column ${ }^{54}$ and some microbes could be even aerosolised more efficiently than others $^{55}$. Thus, the potential contribution of marine microbes may be underestimated by this simple approach.

Additionally, the height of the ABL over land and ocean was computed as the average height of the NCEP/NCAR atmospheric reanalysis data of the potential temperature profiles corresponding to a potential temperature at least two degrees greater than the minimum temperature. Average values for the period between 1 January 1981 and 31 December 2010 were $817 \pm 266 \mathrm{~m}$ (average \pm SD) over the oceans and $564 \pm 342 \mathrm{~m}$ over land similar to those reported by von Engel and Texeira $^{33}$ for the period $1999-2009$.

Residence times. The residence time in the atmosphere for $50 \%$ of total sampled microorganisms in each location was calculated using the equation proposed by Mayol et al. ${ }^{2}$ that describes the remaining microbial load in the atmosphere as function of time and $v_{\mathrm{d}}$. To evaluate the effective distance that $50 \%$ of the particles can travel following the HYSPLIT ${ }^{30}$ forward trajectories of air masses at $10 \mathrm{~m}$ high the maximum distance from the origin was considered during the respective residence times.

Upscaling. The total load of microorganisms over the extension compressed between $40^{\circ} \mathrm{S}$ and $40^{\circ} \mathrm{N}$ was estimated by first determining the exponential fit between the observed prokaryotic and eukaryotic loads and their corresponding distances to the nearest land mass (Supplementary Fig. 10) and second by upscaling the loads to a regular grid of $1^{\circ} \times 1^{\circ}$ covering the domain. The distances to the nearest land mass of each of the average positions of the ship during the $6 \mathrm{~h}$ of sampling and each of the grid points were obtained by using the GEBCO bathymetry of $1 \times 1 \mathrm{~min}$ of spatial resolution (http://www.gebco.net). The estimated load at each grid point was multiplied by its corresponding cell grid area and finally added over the $40^{\circ} \mathrm{S}$ and $40^{\circ} \mathrm{N}$ region resulting in the total load value. Abundances of airborne prokaryotes $\mathrm{m}^{-3}$ and eukaryotes $\mathrm{m}^{-3}$ of air were upscaled at $1^{\circ} \times 1^{\circ}$ resolution following the same procedure than for the estimated loads. The upscaled abundances were then interpolated to the NCEP/NCAR grid $\left(2.5^{\circ} \times 2.5^{\circ}\right)$ and used together with the 2011 annual mean of atmospheric fields from the 
NCEP/NCAR reanalysis (wind speed, relative humidity, air temperature and mean sea level pressure) to estimate the deposition fluxes encompassed between $40^{\circ} \mathrm{S}$ and $40^{\circ} \mathrm{N}$. The spray fluxes over the study area were estimated by taking into account the minimum and maximum values of the observed abundances of prokaryotes on the sea surface water.

Data availability. The measured abundances and calculated fluxes of microbes reported in this paper are included as Supplementary Information. The original sequences of airborne microbes reported in this study are available at the Sequence Read Archive (SRA, http://www.ncbi.nlm.nih.gov/sra/SRP074223) under Bioproject ID PRJNA319484 with accession numbers SAMN04903953 to SAMN04904051.

Received: 6 May 2016 Accepted: 1 June 2017

Published online: 04 August 2017

\section{References}

1. Burrows, S. M., Elbert, W., Lawrence, M. G. \& Pöschl, U. Bacteria in the global atmosphere-part 1: review and synthesis of literature data for different ecosystems. Atmos. Chem. Phys. 9, 9263-9280 (2009).

2. Mayol, E., Jiménez, M. A., Herndl, G. J., Duarte, C. M. \& Arrieta, J. M. Resolving the abundance and air-sea fluxes of airborne microorganisms in the North Atlantic Ocean. Front. Microbiol. 5, 557 (2014).

3. Spracklen, D. V. \& Heald, C. L. The contribution of fungal spores and bacteria to regional and global aerosol number and ice nucleation immersion freezing rates. Atmos. Chem. Phys. 14, 9051-9059 (2014).

4. Burrows, S. M. et al. Bacteria in the global atmosphere-Part 2: Modeling of emissions and transport between different ecosystems. Atmos. Chem. Phys. 9, 9281-9297 (2009).

5. O'Dowd, C. D. \& Leeuw, G.de. Marine aerosol production: a review of the current knowledge. Philos. Trans. R. Soc. Math. Phys. Eng. Sci. 365, 1753-1774 (2007).

6. Morris, C. E. et al. Bioprecipitation: a feedback cycle linking Earth history, ecosystem dynamics and land use through biological ice nucleators in the atmosphere. Glob. Change Biol. 20, 341-351 (2014).

7. Wilson, T. W. et al. A marine biogenic source of atmospheric ice-nucleating particles. Nature 525, 234-238 (2015).

8. Möhler, O., DeMott, P. J., Vali, G. \& Levin, Z. Microbiology and atmospheric processes: the role of biological particles in cloud physics. Biogeosciences 4, 1059-1071 (2007).

9. Fröhlich-Nowoisky, J. et al. Biogeography in the air: fungal diversity over land and oceans. Biogeosciences 9, 1125-1136 (2012).

10. Hervàs, A., Camarero, L., Reche, I. \& Casamayor, E. O. Viability and potential for immigration of airborne bacteria from Africa that reach high mountain lakes in Europe. Environ. Microbiol. 11, 1612-1623 (2009).

11. Polymenakou, P. N. Atmosphere: a source of pathogenic or beneficial microbes? Atmosphere 3, 87-102 (2012).

12. Singh, R. P. et al. The emergence of Ug99 races of the stem rust fungus is a threat to world wheat production. Annu. Rev. Phytopathol. 49, 465-481 (2011).

13. Matthias-Maser, S., Brinkmann, J. \& Schneider, W. The size distribution of marine atmospheric aerosol with regard to primary biological aerosol particles over the South Atlantic Ocean. Atmos. Environ. 33, 3569-3575 (1999).

14. Cho, B. C. \& Hwang, C. Y. Prokaryotic abundance and 16S rRNA gene sequences detected in marine aerosols on the East Sea (Korea): prokaryotes above the East Sea. FEMS Microbiol. Ecol. 76, 327-341 (2011).

15. DeLeon-Rodriguez, N. et al. Microbiome of the upper troposphere: species composition and prevalence, effects of tropical storms, and atmospheric implications. Proc. Natl Acad. Sci. USA 110, 2575-2580 (2013).

16. Willeke, K. \& Whitby, K. T. Atmospheric aerosols: size distribution interpretation. J. Air Pollut. Control Assoc. 25, 529-534 (1975).

17. Seinfeld, J. H. \& Pandis, S. N. Atmospheric Chemistry and Physics: From Air Pollution to Climate Change (John Willey \& Sons, 1998)

18. Jurado, E., Dachs, J., Duarte, C. M. \& Simó, R. Atmospheric deposition of organic and black carbon to the global oceans. Atmos. Environ. 42, 7931-7939 (2008).

19. Andreas, E. L. A new sea spray generation function for wind speeds up to $32 \mathrm{~m} \mathrm{~s}^{-1}$. J. Phys. Oceanogr. 28, 2175-2184 (1998).

20. Jurado, E. et al. Atmospheric dry deposition of persistent organic pollutants to the atlantic and inferences for the global oceans. Environ. Sci. Technol. 38, 5505-5513 (2004)

21. Kellogg, C. A. \& Griffin, D. W. Aerobiology and the global transport of desert dust. Trends Ecol. Evol. 21, 638-644 (2006).
22. NASA. Aerosol Optical Thickness (1 month - Aqua/MODIS). Aerosol Optical Thickness (1 month - Aqua/MODIS). Available at https://neo.sci.gsfc.nasa.gov/ view.php?datasetId=MYDAL2_M_AER_OD\&date=2011-05-09 (2011).

23. Wu, P.-C., Tsai, J.-C., Li, F.-C., Lung, S.-C. \& Su, H.-J. Increased levels of ambient fungal spores in Taiwan are associated with dust events from China. Atmos. Environ. 38, 4879-4886 (2004).

24. Reponen, T., Grinshpun, S. A., Conwell, K. L., Wiest, J. \& Anderson, M. Aerodynamic versus physical size of spores: measurement and implication for respiratory deposition. Grana 40, 119-125 (2001).

25. Kunkel, D. et al. Urban emission hot spots as sources for remote aerosol deposition: remote aerosol deposition. Geophys. Res. Lett. 39, L01808 (2012).

26. González-Gaya, B., Zúñiga-Rival, J., Ojeda, M.-J., Jiménez, B. \& Dachs, J. Field measurements of the atmospheric dry deposition fluxes and velocities of polycyclic aromatic hydrocarbons to the global oceans. Environ. Sci. Technol. 48, 5583-5592 (2014).

27. Ramana, M. V., Krishnan, P., Nair, S. M. \& Kunhikrishnan, P. K. Thermodynamic structure of the atmospheric boundary layer over the Arabian Sea and the Indian Ocean during pre-INDOEX and INDOEX-FFP campaigns. Ann. Geophys. 22, 2679-2691 (2004).

28. Kirchman, D. L. Processes in Microbial Ecology (Oxford University Press, 2012)

29. Jurado, E. et al. Wet deposition of persistent organic pollutants to the global oceans. Environ. Sci. Technol. 39, 2426-2435 (2005).

30. Stein, A. F. et al. NOAA's HYSPLIT Atmospheric Transport and Dispersion Modeling System. Bull. Am. Meteorol. Soc. 96, 2059-2077 (2015).

31. Després, V. R. et al. Primary biological aerosol particles in the atmosphere: a review. Tellus B 64, 15598 (2012).

32. Archer, C. L. \& Jacobson, M. Z. Evaluation of global wind power. J. Geophys. Res. Atmospheres 110, D12110 (2005).

33. von Engeln, A. \& Teixeira, J. A planetary boundary layer height climatology derived from ECMWF reanalysis data. J. Clim. 26, 6575-6590 (2013).

34. Duarte, C. M. Seafaring in the 21st century: the Malaspina 2010 Circumnavigation Expedition. Limnol. Oceanogr. Bull. 24, 11-14 (2015)

35. Kistler, R. et al. The NCEP-NCAR 50-year reanalysis: monthly means CD-ROM and documentation. Bull. Am. Meteorol. Soc. 82, 247-267 (2001).

36. Carvalho, E. et al. Performance of the Coriolis air sampler, a high-volume aerosol-collection system for quantification of airborne spores and pollen grains. Aerobiologia 24, 191-201 (2008).

37. Marie, D., Partensky, F., Jacquet, S. \& Vaulot, D. Enumeration and cell cycle analysis of natural populations of marine picoplankton by flow cytometry using the nucleic acid stain SYBR Green I. Appl. Environ. Microbiol. 63, 186-193 (1997).

38. Fukuda, R., Ogawa, H., Nagata, T. \& Koike, I. Direct determination of carbon and nitrogen contents of natural bacterial assemblages in marine environments. Appl. Environ. Microbiol. 64, 3352-3358 (1998).

39. Bauer, H. et al. Determination of the carbon content of airborne fungal spores. Anal. Chem. 74, 91-95 (2002).

40. Troen, I. B. \& Mahrt, L. A simple model of the atmospheric boundary layer; sensitivity to surface evaporation. Bound. Layer Meteorol. 37, 129-148 (1986).

41. Dee, D. P. et al. The ERA-interim reanalysis: configuration and performance of the data assimilation system. Q. J. R. Meteorol. Soc. 137, 553-597 (2011).

42. Wyngaard, J. C. \& Brost, R. A. Top-down and bottom-up diffusion of a scalar in the convective boundary layer. J. Atmos. Sci. 41, 102-112 (1984).

43. Bates, S. T. et al. Examining the global distribution of dominant archaeal populations in soil. ISME J. 5, 908-917 (2011).

44. Bates, S. T., Cropsey, G. W. G., Caporaso, J. G., Knight, R. \& Fierer, N. Bacterial communities associated with the lichen symbiosis. Appl. Environ. Microbiol. 77, 1309-1314 (2011).

45. Liu, Z., Lozupone, C., Hamady, M., Bushman, F. D. \& Knight, R. Short pyrosequencing reads suffice for accurate microbial community analysis. Nucleic Acids Res. 35, e120 (2007).

46. Caporaso, J. G. et al. QIIME allows analysis of high-throughput community sequencing data. Nat. Methods 7, 335-336 (2010).

47. Pruesse, E. et al. SILVA: a comprehensive online resource for quality checked and aligned ribosomal RNA sequence data compatible with ARB. Nucleic Acids Res. 35, 7188-7196 (2007).

48. Knights, D. et al. Bayesian community-wide culture-independent microbial source tracking. Nat. Methods 8, 761-763 (2011).

49. Williams, R. M. A model for the dry deposition of particles to natural water surfaces. Atmos. Environ. 1967 16, 1933-1938 (1982).

50. Bakken, L. R. \& Olsen, R. A. Buoyant densities and dry-matter contents of microorganisms: conversion of a measured biovolume into biomass. Appl. Environ. Microbiol. 45, 1188-1195 (1983).

51. Gong, S. L. A parameterization of sea-salt aerosol source function for sub- and super-micron particles: sea-salt aerosol production. Glob. Biogeochem. Cycles 17, 1097 (2003). 
52. Lewis, E. R., Schwartz, S. E., Lewis, E. R. \& Schwartz, S. E. Sea Salt Aerosol Production: Mechanisms, Methods, Measurements and Models-A Critical Review 9-99 (American Geophysical Union, 2004).

53. Li, W. K. W. Annual average abundance of heterotrophic bacteria and Synechococcus in surface ocean waters. Limnol. Oceanogr. 43, 1746-1753 (1998).

54. Blanchard, D. C. \& Syzdek, L. D. Water-to-air transfer and enrichment of bacteria in drops from bursting bubbles. Appl. Environ. Microbiol. 43, 1001-1005 (1982).

55. Fahlgren, C. et al. Seawater mesocosm experiments in the Arctic uncover differential transfer of marine bacteria to aerosols. Environ. Microbiol. Rep. 7, 460-470 (2015).

\section{Acknowledgements}

This is a contribution to the Malaspina Expedition 2010, funded by the INGENIO 2010 CONSOLIDER program (ref. CDS2008-00077) of the Spanish Ministry of Economy and Competitiveness. We thank the crew of R/V Hespérides for their invaluable support and for providing the chlorophyll data, J. Baldrich Justel for his help with processing samples and the NOAA Air Resources Laboratory (ARL) for the provision of the HYSPLIT model (http://www.ready.noaa.gov) used in this publication. E.M. and M.A.J. acknowledge the 'Junta para la Ampliación de Estudios' program (JAE-predoc and JAE-doc contracts, respectively) from CSIC, supplied by the European Social Fund. A.M.-A. acknowledges an FPI grant funded by the Spanish Ministry of Science and Innovation. B.G.-G. acknowledges a predoctoral fellowship from the BBVA Foundation. We thank the Boundary-Layer Height data and the NCEP atmospheric reanalysis provided by the NOAA-ESRL Physical Sciences Division, Boulder, Colorado from their Web site at http://www.esrl.noaa.gov/psd/. Bathymetry was obtained from the GEBCO Digital Atlas published by the British Oceanographic Data Centre, on behalf of IOC and IHO, 2003.

\section{Author contributions}

E.M. carried out part of the sampling, performed the counting of microorganisms, contributed to the DNA amplifications and purifications, and prepared the manuscript. J.M.A. designed and tested the sampling protocols, calculated backward and forward trajectories and analysed the sequencing data. M.A.J. carried out the calculations of spray and deposition fluxes, calculation of the BLH and distances transported by microorganisms. A.M.-A. carried out the calculations of distances to nearest land mass, contributed to develop the upscaling of loads and fluxes of airborne microbes, and calculated the wind-wave component of the significant wave height (SWHw). N.G.B. contributed with the DNA extraction and DNA amplification. J.D. performed the calculations of wet deposition fluxes and contributed to the discussion of results. B.G.-G. contributed to calculate the wet deposition fluxes and participated in the air sampling. S. J.R. carried out part of the air sampling. V.M.B.-B. and E.F.-N. provided the calibration and quality control of meteorological data. C.M.D. designed the Malaspina $2010 \mathrm{Cir}-$ cumnavigation Expedition and contributed to the design of this work. All authors discussed the results and contributed to the manuscript.

\section{Additional information}

Supplementary Information accompanies this paper at doi:10.1038/s41467-017-00110-9.

Competing interests: The authors declare no competing financial interests.

Reprints and permission information is available online at http://npg.nature.com/ reprintsandpermissions/

Publisher's note: Springer Nature remains neutral with regard to jurisdictional claims in published maps and institutional affiliations.

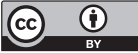

Open Access This article is licensed under a Creative Commons Attribution 4.0 International License, which permits use, sharing, adaptation, distribution and reproduction in any medium or format, as long as you give appropriate credit to the original author(s) and the source, provide a link to the Creative Commons license, and indicate if changes were made. The images or other third party material in this article are included in the article's Creative Commons license, unless indicated otherwise in a credit line to the material. If material is not included in the article's Creative Commons license and your intended use is not permitted by statutory regulation or exceeds the permitted use, you will need to obtain permission directly from the copyright holder. To view a copy of this license, visit http://creativecommons.org/ licenses/by/4.0/.

(c) The Author(s) 2017 